This is the peer reviewed version of the following article: [FULL CITE: http://onlinelibrary.wiley.com/ doi/10.1002/chem.201604282/abstract], which has been published in final form at [Link to final article using the DOI: 10.1002/chem.201604282]. This article may be used for non-commercial purposes in accordance with Wiley Terms and Conditions for Self-Archiving.

\title{
Effect of substituents and initial degree of functionalization of alkylated single- walled carbon nanotubes on their thermal stability and photoluminescence properties
}

Yutaka Maeda, ${ }^{[\mathrm{[a]}}$ Yuya Takehana, ${ }^{[\mathrm{a}]}$ Jing-Shuang Dang, ${ }^{[\mathrm{b}]}$ Mitsuaki Suzuki, ${ }^{[\mathrm{a}, \mathrm{c}]}$ Michio Yamada, ${ }^{[\mathrm{a}]}$ and Shigeru Nagase ${ }^{*[\mathrm{~b}]}$

[a] Prof. Dr. Y. Maead, Mr. Y. Takehana, Prof. Dr. M. Suzuki, Prof. Dr. M. Yamada, Department of Chemistry, Tokyo Gakugei University,

Tokyo 184-8501 (Japan)

E-mail: ymaeda@u-gakugei.ac.jp

[b] Dr. J.-S. Dang, Prof. Dr. S. Nagase

Fukui Institute for Fundamental Chemistry, Kyoto University, Kyoto 606-8103 (Japan)

E-mail: nagase@ims.ac.jp

[c] Prof. Dr. M. Suzuki,

Department of Chemistry, Faculty of Science, Josai University, Sakado 3500295 (Japan)

Supporting information for this article is given via a link at the end of the document.

Abstract: Alkylated SWNTs were thermally treated to determine the influence of the substituents and the degree of functionalization on their thermal stability and photoluminescence (PL) properties. Alkylated SWNTs were prepared using sodium naphthalenide and alkyl bromide. The defunctionalization of alkylated SWNTs was monitored by absorption and Raman spectra. A selective recovery of the characteristic absorption and RBM peaks were observed during the thermal treatment, which indicates 
that the thermal stability of alkylated SWNTs decreased with an increase in SWNT diameter and with an increase in the degree of functionalization. $n$-Butylated SWNTs and phenethylated SWNTs showed higher thermal stability than sec-butylated SWNTs and benzylated SWNTs for a similar degree of functionalization, respectively. The diameter selectivity and effect of substituents on the thermal elimination reaction were confirmed by using density functional theory. In addition, it was shown that the initial degree of functionalization of alkylated SWNTs, where the alkyl group and degree of functionalization after thermal treatment were kept constant, strongly affects their PL properties, Stokes shift, and PL peak intensity.

\section{Introduction}

Introducing functional groups onto single-walled carbon nanotubes (SWNTs) affects not only their dispersibility but also their optical and electronic properties. ${ }^{[1-4]}$ Recently, much interest has been focused on SWNT functionalization to induce new and bright photoluminescence (PL) peaks. The enhanced near-infrared (NIR) PL peaks can be useful in biological imaging owing to the high transparency of biological tissues to NIR light. ${ }^{[5-}$ ${ }^{14]}$ However, SWNTs lose their intrinsic properties with excessive functionalization upon disrupting the $\pi$-conjugation of the SWNTs. ${ }^{[15,16]}$ Accordingly, it is important to control the degree of functionalization to prepare functionalized SWNTs that possess the desired properties. Thermogravimetric analysis (TGA) measures weight loss to estimate the degree of functionalization of SWNTs. ${ }^{[17]}$ Hirsch et al. have studied in detail the elimination of species from hexylated SWNTs using thermogravimetric-mass spectrometric analysis. ${ }^{[18]}$ In 2015, Weisman et al. reported that the diameter-selective defunctionalization of dodecylated SWNTs occurred by thermal treatment. They also proposed that the diameter-selective thermal elimination reaction could separate SWNT mixtures depending on their diameters. ${ }^{[19]}$ We have previously reported that the two-step reductive alkylation using $\mathrm{LiR}^{1}$ and $\mathrm{R}^{2} \mathrm{Br}$ and subsequent thermal treatment of $\mathrm{R}^{1}$ SWNTs- ${ }^{2}$ generated new PL peaks in the NIR region. ${ }^{[10,20,21]}$ The results indicate that thermal treatment can effectively control the degree of functionalization of SWNTs. During thermal treatment, weight loss was observed in both dibutylated SWNTs, $n B u-$ SWNTs-sBu and $t \mathrm{Bu}-\mathrm{SWNTs}-\mathrm{BBu}$, at relatively low temperature, compared to the other dibutylated SWNTs, such as $n B u-S W N T s-n B u$. Unfortunately, because the ratio of butyl stereoisomers (e.g. $n \mathrm{Bu} / \mathrm{sBu}$ of $n \mathrm{Bu}-(6,5) \mathrm{SWNTs}-\mathrm{sBu}$ ) was not determined, it was 
difficult to quantify the cause of the different thermal stability of Bu-SWNTs-Bu. In this work, we perform thermal treatments of different alkylated SWNTs (SWNTs-R) to show the substituent effect and the influence of the degree of functionalization on the thermal elimination reaction. In addition, we characterize the PL properties of SWNTs-R before and after the thermal treatment.

\section{Results and discussion}

SWNTs-R was prepared from $(6,5)$-enriched SWNTs using sodium naphthalenide and alkyl bromide (Scheme 1). ${ }^{[21,22]}$ The degree of functionalization of SWNTs-R was controlled by changes to the synthetic protocol and the amount of reagents used (see experimental section). Hereafter, highly and lightly functionalized SWNTs-R will be referred to as SWNTs-R(H) and SWNTs-R(L), respectively.

SWNTs-R was treated for $6 \mathrm{~h}$ at a maximum temperature of 150,200 , or $600^{\circ} \mathrm{C}$ and was characterized with absorption and Raman spectroscopy (Figures 1 \& S1). After the thermal treatment, the characteristic absorption and RBM peaks, assigned to the large diameter SWNTs, recovered preferentially. (Diameter selectivity was also confirmed using HiPco SWNTs; see supporting information.) The peak ratio of the D to G band (D/G) and the $\mathrm{E}_{11}$ absorption ratio of SWNTs and SWNTs-R at $\sim 976 \mathrm{~nm}$ are summarized in Table 1. The $E_{11}$ absorption ratio ([E $E_{11}$ peak intensity of SWNTs-R] / [ $E_{11}$ peak intensity of SWNTs]) was estimated from the absorption spectra, normalized at the peak minimum of $\sim 775 \mathrm{~nm}$ (See Figure S3). This local minimum was selected because the absorption intensity at $\sim 775 \mathrm{~nm}$ changes only slightly, compared to the intensity of the characteristic $\mathrm{E}_{11}$ peak at $\sim 976 \mathrm{~nm}$ in the photochemical reaction of SWNTs with aliphatic amines. ${ }^{[23]}$ Figure 2 shows the $E_{11}$ absorption ratio as a function of treatment temperature. The $\mathrm{E}_{11}$ absorption ratios of SWNTs- $n \mathrm{Bu}(\mathrm{L})$ and SWNTs-sBu(H) were estimated to be 0.52, respectively, indicating a similar degree of functionalization. Interestingly, the $\mathrm{E}_{11}$ absorption intensity of SWNTs-sBu(H) was significantly recovered by thermal treatment at $150^{\circ} \mathrm{C}$, although that of SWNTs- $n \mathrm{Bu}(\mathrm{L})$ showed little change when exposed to the same thermal treatment. Similar differences were observed between SWNTs-Bn(H) and SWNTs-Phenethyl(H) and SWNTs-Bn(L) and SWNTs-Phenethyl(L). In addition, the thermal stability of SWNTs-R(H) was lower than that of SWNTs-R(L) when the same alkyl group was introduced $(\mathrm{R}=n \mathrm{Bu}$ or phenethyl). Thus, both the substituents and the degree of functionalization are important factors affecting the thermal stability of 
functionalized SWNTs.

To clarify the effect of the substituents on the thermal elimination reaction, the bonddissociation energy of $\left({ }^{1} \mathrm{R}-\mathrm{SWNTs}\right)-t \mathrm{Bu}\left({ }^{1} \mathrm{R}=n \mathrm{Bu}\right.$ and $\left.t \mathrm{Bu}\right)$ and alkylated SWNT radical $\left({ }^{1} \mathrm{R}-(\mathrm{SWNTs}\right.$ radical)) was calculated using density functional theory. Hydrogenterminated (n,n)-SWNT structures were employed for this calculation. The 1,4-isomer, which is more energetically stable than the 1,2- and 1,8-isomers in $(6,6)$ SWNT, was chosen for the calculation (Figure 3). The calculations showed that the bond-dissociation energy of $\left({ }^{1} \mathrm{R}-\mathrm{SWNTs}\right)-t \mathrm{Bu}\left({ }^{1} \mathrm{R}=n \mathrm{Bu}\right.$ and $\left.t \mathrm{Bu}\right)$ is lower than that of $\left({ }^{1} \mathrm{R}-\mathrm{SWNTs}\right)-n \mathrm{Bu}$ (Table 2). The results suggest that the alkyl group elimination reaction is strongly influenced by the stability of the leaving groups. In addition, the bond-dissociation energy decreased with an increase in SWNT diameter. Therefore, these theoretical results are in good accordance with the experimental results.

Two new PL peaks at $1100\left(\mathrm{E}_{11} *\right)$ and $1230 \mathrm{~nm} \quad\left(\mathrm{E}_{11} * *\right)$ appeared, accompanied by the intrinsic $E_{11}$ PL peakn the PL spectra of SWNTs-R (Figure 4). The E 11 PL peak intensities altered as a function of the thermal treatment conditions. Especially, SWNTs$n \mathrm{Bu}(\mathrm{L})$ and SWNTs-Phenethyl(L) showed a strong emission at $\sim 1100 \mathrm{~nm}$ after thermal treatment at $150^{\circ} \mathrm{C}$. Interestingly, the PL spectral features differed between the two pairs of SWNT-R: SWNTs- ${ }^{n} \mathrm{Bu}(\mathrm{L}) 150^{\circ} \mathrm{C}$ and SWNTs- ${ }^{n} \mathrm{Bu}(\mathrm{H}) 200^{\circ} \mathrm{C}$, and SWNTs-Phenethyl(L) $150^{\circ} \mathrm{C}$ and SWNTs-Phenethyl $(\mathrm{H}) 200^{\circ} \mathrm{C}$, even though the spectral features of absorption and the substituent were the same (Figure 5). The results indicate that the degree of functionalization of SWNTs-R before the thermal treatment affects the PL properties of SWNTs-R after the thermal treatment. Recently, we reported that the $\mathrm{E}_{11}{ }^{* *}$ PL peak selectively occurs in the PL spectra of alkylated SWNTs, which are prepared using sodium naphthalenide and $\alpha, \alpha^{\prime}$-dibromo-o-xylene. On the other hand, the $\mathrm{E}_{11}{ }^{*}$ and $\mathrm{E}_{11}{ }^{* *} \mathrm{PL}$ peaks occur in the PL spectra of the alkylated SWNTs, which are prepared using sodium naphthalenide and alkyl bromide. ${ }^{[13]}$ On the basis of these results, we proposed that the PL properties induced by chemical functionalization are strongly influenced by the spacing between the carbon atom addition sites. Therefore, the difference in the PL properties between the pairs of SWNTs-R could be due to the difference in the positional relationships of alkyl sites on the SWNTs-R, rather than the degree of functionalization. The control of Stokes shift by the addition reaction and subsequent thermal reaction is important because it strongly affects their PL lifetime and up-conversion PL efficiency. ${ }^{[13]}$ 


\section{Conclusions}

In conclusion, we have investigated the substituent effect and the influence of the degree of functionalization on the thermal elimination reaction and PL properties of alkylated SWNTs. The defunctionalization of elimination reaction of alkylated SWNTs was monitored by absorption and Raman spectra, respectively. The selective recovery of the characteristic absorption, RBM peak intensities, and D/G ratio indicate that the thermal stability of SWNTs-R decreased with an increase in SWNT diameter and with an increase in the degree of functionalization. In addition, thermal stability is strongly affected by the type of substituent used to functionalize the SWNTs. This result was supported by the bond-dissociation energy of SWNTs-R, calculated using the DFT method. SWNTs-R possessing the same substituent and similar absorption spectral features were successfully prepared from SWNTs-R(H) and SWNTs-R(L) through thermal treatment. Interestingly, different PL properties were observed for these SWNTs-R, indicating that the PL properties are strongly influenced by the initial degree of functionalization. The different PL properties observed could be due to the difference in the positional relationships of alkyl sites on the SWNTs-R. This opens new possibilities to control the optical properties of SWNTs through a combination of addition and elimination reactions.

\section{Experimental Section}

\section{A typical procedure for reductive alkylation (lightly functionalized SWNTs-R)}

Naphthalene (367 mg, $2.86 \mathrm{mmol}$ ) and sodium (108 mg, $4.70 \mathrm{mmol}$ ) were placed in a $200 \mathrm{~mL}$ heat-dried three-necked round-bottom flask under argon. Anhydrous tetrahydrofuran $(100 \mathrm{~mL})$ was then added to the flask and the contents were stirred for 1 h. A portion (10.0 mg) of SWNTs was placed in a $200 \mathrm{~mL}$ heat-dried three-necked roundbottom flask under argon. The sodium naphthalenide solution was added to the SWNTs, which were then sonicated for $1 \mathrm{~h}$. Alkyl bromide (3.42 mmol) was subsequently added to the mixture. The mixture was sonicated for $30 \mathrm{~min}$ and then quenched by the addition of $30 \mathrm{~mL}$ of dry ethanol. Afterwards, the reaction mixture was washed with water and diluted in $10 \%$ aq. $\mathrm{HCl}$. This mixture was then subsequently washed with aq. $\mathrm{NaHCO}_{3}$ until a neutral $\mathrm{pH}$ value was obtained. The resulting suspended black solid was collected by filtration using a membrane filter (PTFE, $1.0 \mu \mathrm{m}$ ) and washed with tetrahydrofuran, 
methanol, and dichloromethane via the dispersion-filtration process. The solid was then dried under vacuum at $50^{\circ} \mathrm{C}$.

\section{A typical procedure for reductive alkylation (highly functionalized SWNTs-R)} A portion (10.0 mg) of SWNTs, naphthalene (1833 mg, $14.3 \mathrm{mmol}$ ), and sodium (540 mg, $23.5 \mathrm{mmol}$ ) were placed in a $200 \mathrm{~mL}$ heat-dried three-necked round-bottom flask under argon. Anhydrous tetrahydrofuran $(100 \mathrm{~mL})$ was then added to the flask and the contents were stirred for $1 \mathrm{~h}$, and then sonicated for $1 \mathrm{~h}$. The sodium naphthalenide solution containing SWNTs was added to a $100 \mathrm{~mL}$ heat-dried three-necked round-bottom flask under argon. Alkyl bromide (3.42 mmol $\rightarrow 17.1 \mathrm{mmol}$ ) was subsequently added to the mixture. The mixture was sonicated for $30 \mathrm{~min}$ and then quenched by the addition of 30 $\mathrm{mL}$ of dry ethanol. Afterwards, the reaction mixture was washed with water and diluted in $10 \%$ aq. $\mathrm{HCl}$. This mixture was then subsequently washed with aq. $\mathrm{NaHCO}_{3}$ until a neutral $\mathrm{pH}$ value was obtained. The resulting suspended black solid was collected by filtration using a membrane filter (PTFE, $1.0 \mu \mathrm{m}$ ) and washed with tetrahydrofuran, methanol, and dichloromethane via the dispersion-filtration process. The solid was then dried under vacuum at $50^{\circ} \mathrm{C}$.

\section{Thermal treatment of alkylated SWNTs (SWNTs-R)}

The SWNTs-R was thermally treated at a heating rate of $10^{\circ} \mathrm{C} \min ^{-1}$ and a nitrogen flow rate of $50 \mathrm{~mL} \mathrm{~min}^{-1}$ in a thermogravimetric analyzer (TG-50A; Shimadzu Corp.). After reaching the target temperature, the SWNTs-R were continuously heated for $6 \mathrm{~h}$, and then the heating furnace was cooled using a cooling blower (BLW-50 cooling blower; Shimadzu Corp.).

\section{Preparation of a SWNT dispersion using SDBS in $\mathrm{D}_{2} \mathrm{O}$}

A portion of SWNTs or functionalized SWNTs (SWNTs-R) was added to $4 \mathrm{~mL}$ of $\mathrm{D}_{2} \mathrm{O}$ containing $1 \mathrm{wt} \%$ sodium dodecylbenzenesulfonate (SDBS) and sonicated for $1.5 \mathrm{~h}$ in a bath-type sonicator (Branson ultrasonic cleaner $2510 \mathrm{~J}-\mathrm{MT}$ ). This suspension was then centrifuged for $1 \mathrm{~h}$ at 140,000g. The absorption intensity at $775 \mathrm{~nm}$ was adjusted, by adding an adequate dose of $\mathrm{D}_{2} \mathrm{O}$ solution containing $1 \mathrm{wt} \%$ SDBS to the supernatant solution. After $10 \mathrm{~min}$ of sonication, the resulting suspension was centrifuged for $1 \mathrm{~h}$ at $140,000 \mathrm{~g}$. 


\section{Theoretical studies:}

A hydrogen-terminated (5,5)-, (6,6)-, (7,7)-, and (8,8)-SWNT structure containing 21 carbon layers was employed in this study. Structural optimization was performed using Gaussian 09 Revision D.01 ${ }^{[24]}$ within the DFT framework using the B3LYP functional ${ }^{[25,26]}$ in conjunction with the $3-21 \mathrm{G}$ basis set.

\section{Acknowledgements}

Financial support from the Grants-in-Aid for Scientific Research (26286012) funded by the Ministry of Education, Culture, Sports, Science, and Technology of Japan is gratefully acknowledged.

Keywords: carbon nanotubes • density functional calculations $\bullet$ NIR photoluminescence

- thermal stability • degree of functionalizaiton

[1] S. Iijima, T. Ichihashi, Nature 1993, 363, 603-605.

[2] D. S.Bethune, C. H. Kiang, M. S. De Vries, G. Gorman, R. Savoy, J. Vazquez, R. Beyers, Nature 1993, 363, 605-607.

[3] D. Tasis, N. Tagmatarchis, A. Bianco, M. Prato, Chem. Rev. 2006, 106, 1105-1136.

[4] N. Karousis, N. Tagmatarchis, D. Tasis, Chem. Rev. 2010, 110, 5366-5397.

[5] S. Ghosh, S. M. Bachilo, R. A. Simonette, K. M. Beckingham, R. B. Weisman, Science 2010, 330, 1656-1659.

[6] Y. Maeda, J. Higo, Y. Amagai, J. Matsui, K. Ohkubo, Y. Yoshigoe, M. Hashimoto, K. Eguchi, M. Yamada, T. Hasegawa, Y. Sato, J. Zhou, J. Lu, T. Miyashita, S. Fukuzumi, T. Murakami, K. Tohji, S. Nagase, T. Akasaka, J. Am. Chem. Soc. 2013, 135, 6356-6362. [7] Y. Miyauchi, M. Iwamura, S. Mouri, T. Kawazoe, M. Ohtsu, K. Matsuda, Nat. Photon. 2013, 7, 715-719.

[8] Y. Piao, B. Meany, L. R. Powell, N. Valley, H. Kwon, G. C. Schatz, Y. Wang, Nat. Chem. 2013, 5, 840-845.

[9] Y. Zhang, N. Valley, A. H. Brozena, Y. Piao, X. Song, G. C. Schatz, Y. Wang, J. Phys. Chem. Lett. 2013, 4, 826-830.

[10] Y. Maeda, Y. Takehana, M. Yamada, M. Suzuki, T. Murakami, Chem. Commun. 2015, $51,13462-13465$.

[11] H. Kwon, A. Furmanchuk, M. Kim, B. Meany, Y. Guo, G. C. Schatz, Y. Wang, J. Am. 
Chem. Soc. 2016, 138, 6878-6885.

[12] T. Shiraki, T. Shiraishi, G. Juhász, N. Nakashima, Sci. Rep. 2016, 6, 28393.

[13] Y. Maeda, S. Minami, Y. Takehana, J.-S. Dang, S. Aota, K. Matsuda, Y. Miyauchi,

M. Yamada, M. Suzuki, R.-S. Zhao, X. Zhao, S. Nagase, Nanoscale 2016, DOI: 10.1039/C6NR04214G.

[14] Y. Maeda, E. Sone, A. Nishino, Y. Amagai, W.-W. Wang, M. Yamada, M. Suzuki, J.

Matsui, M. Mitsuishi, T. Okazaki, S. Nagase, Chem. Eur. J. DOI: 10.1002/chem.201602944.

[15] J. Chen, M. A. Hamon, H. Hu, Y. Chen, A. M. Rao, P. C. Eklund, R. C. Haddon, Science 1998, 282, 95-98.

[16] H. Hu, B. Zhao, M. A. Hamon, K. Kamaras, M. E. Itkis, R. C. Haddon, J. Am. Chem. Soc. 2003, 125, 14893-14900.

[17] Y. Ying, R. K. Saini, F. Liang, A. K. Sadana, W. E. Billups, Org. Lett 2003, 5, 14711473.

[18] F. Hof, S. Bosch, J. M. Englert, F. Hauke, A. Hirsch, Angew. Chem., Int. Ed. 2012, 51, 11727-11730.

[19] S. Ghosh, F. Wei, S. M. Bachilo, R. H. Hauge, W. E. Billups, R. B. Weisman, ACS Nano 2015, 9, 6324-6332.

[20] Y. Maeda, T. Kato, T. Hasegawa, M. Kako, T. Akasaka, J. Lu, S. Nagase, Org. Lett. 2010, 12, 996-999.

[21] Y. Maeda, K. Saito, N. Akamatsu, Y. Chiba, S. Ohno, Y. Okui, M. Yamada, T. Hasegawa, M. Kako, T. Akasaka, J. Am. Chem. Soc. 2012, 134, 18101-18108.

[22] J.-Y. Mevellec, C. Bergeret, J. Cousseau, J.-P. Buisson, Ewels, S. Lefrant, J. Am. Chem. Soc. 2011, 133, 16938-16946.

[23] Y. Maeda, Y. Hasuike, K. Ohkubo, A. Tashiro, S. Kaneko, M. Kikuta, M. Yamada, T. Hasegawa, T. Akasaka, J. Zhou, J. Lu, S. Nagase, S. Fukuzumi, ChemPhysChem, 2014, 15, 1821-1826.

[24] Gaussian 09, Revision D.01, M. J. Frisch, G. W. Trucks, H. B. Schlegel, G. E. Scuseria, M. A. Robb, J. R. Cheeseman, G. Scalmani, V. Barone, B. Mennucci, G. A. Petersson, H. Nakatsuji, M. Caricato, X. Li, H. P. Hratchian, A. F. Izmaylov, J. Bloino, G. Zheng, J. L. Sonnenberg, M. Hada, M. Ehara, K. Toyota, R. Fukuda, J. Hasegawa, M. Ishida, T. Nakajima, Y. Honda, O. Kitao, H. Nakai, T. Vreven, J. A. Montgomery, Jr., J. E. Peralta, F. Ogliaro, M. Bearpark, J. J. Heyd, E. Brothers, K. N. Kudin, V. N. Staroverov, 
R. Kobayashi, J. Normand, K. Raghavachari, A. Rendell, J. C. Burant, S. S. Iyengar, J. Tomasi, M. Cossi, N. Rega, J. M. Millam, M. Klene, J. E. Knox, J. B. Cross, V. Bakken, C. Adamo, J. Jaramillo, R. Gomperts, R. E. Stratmann, O. Yazyev, A. J. Austin, R. Cammi, C. Pomelli, J. W. Ochterski, R. L. Martin, K. Morokuma, V. G. Zakrzewski, G. A. Voth, P. Salvador, J. J. Dannenberg, S. Dapprich, A. D. Daniels, Ö. Farkas, J. B. Foresman, J. V. Ortiz, J. Cioslowski, D. J. Fox, Gaussian, Inc., Wallingford CT, 2009.

[25] A. D. Becke, J. Chem. Phys. 1993, 98, 5648-5652.

[26] C. Lee, W. Yang, R. G. Parr, Phys. Rev. B 1988, 37, 785-789. 
Scheme 1.
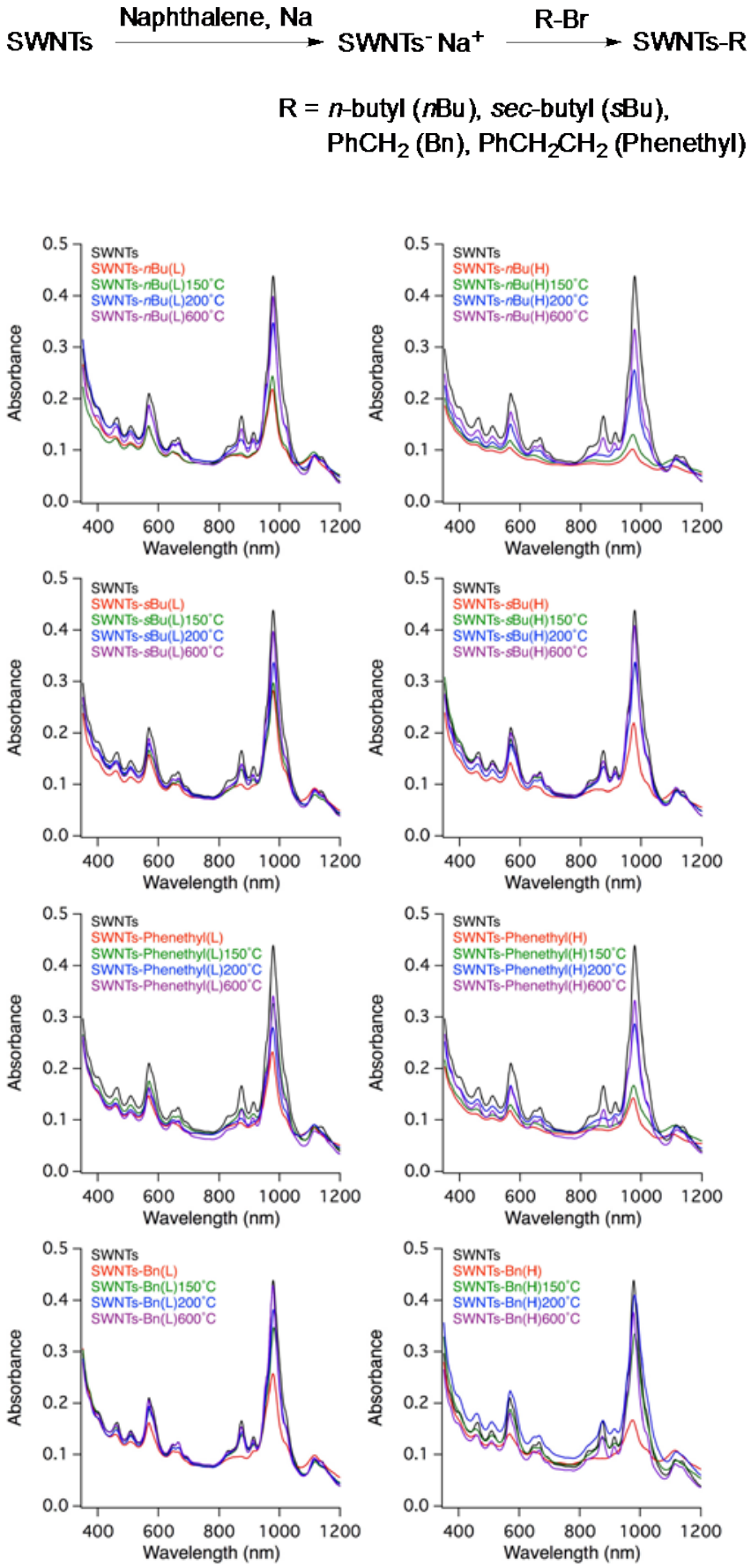

Figure 1. Absorption spectra of SWNTs and SWNTs-R in $\mathrm{D}_{2} \mathrm{O}$ solution containing 1 wt\% SDBS. The samples were observed before and after thermal treatment. 
Table 1. D/G and $E_{11}$ absorption ratio of SWNTs-R before and after the thermal treatment.

\begin{tabular}{|c|c|c|c|}
\hline SWNTS-R & $D / G_{5145 \mathrm{~mm}}$ & $D / G_{633 r m}$ & $\begin{array}{l}\text { absorption } \\
\text { peak ratio }\end{array}$ \\
\hline SWNTs & 0.07 & 0.04 & 1.00 \\
\hline SWNTs- $n B u(L)$ & 0.21 & 0.16 & 0.52 \\
\hline SWNTs- $n \mathrm{Bu}-150^{\circ} \mathrm{C}(\mathrm{L})$ & 0.19 & 0.14 & 0.58 \\
\hline SWNTs- $n$ Bu- $200^{\circ} \mathrm{C}(\mathrm{L})$ & 0.14 & 0.09 & 0.78 \\
\hline SWNTs- $n \mathrm{Bu}-600^{\circ} \mathrm{C}(\mathrm{L})$ & 0.08 & 0.06 & 0.97 \\
\hline$\overline{\text { SWNTs- } n \mathrm{Bu}(\mathrm{H})}$ & 0.42 & 0.36 & 0.25 \\
\hline SWNTs- $n \mathrm{Bu}-150^{\circ} \mathrm{C}(\mathrm{H})$ & 0.33 & 0.31 & 0.31 \\
\hline SWNTs- $n \mathrm{Bu}-200^{\circ} \mathrm{C}(\mathrm{H})$ & 0.19 & 0.14 & 0.62 \\
\hline SWNTs- $n \mathrm{Bu}-600^{\circ} \mathrm{C}(\mathrm{H})$ & 0.08 & 0.05 & 0.80 \\
\hline SWNTs-sBu(L) & 0.17 & 0.12 & 0.69 \\
\hline SWNTs- $s \mathrm{Bu}-150^{\circ} \mathrm{C}(\mathrm{L})$ & 0.10 & 0.07 & 0.72 \\
\hline SWNTs-sBu- $200^{\circ} \mathrm{C}(\mathrm{L})$ & 0.10 & 0.06 & 0.78 \\
\hline SWNTs-sBu- $600^{\circ} \mathrm{C}(\mathrm{L})$ & 0.07 & 0.04 & 0.96 \\
\hline SWNTs-sBu(H) & 0.23 & 0.18 & 0.52 \\
\hline SWNTs-sBu- $150^{\circ} \mathrm{C}(\mathrm{H})$ & 0.14 & 0.10 & 0.73 \\
\hline SWNTs-sBu- $200^{\circ} \mathrm{C}(\mathrm{H})$ & 0.11 & 0.07 & 0.79 \\
\hline SWNTs- $s$ Bu- $600^{\circ} \mathrm{C}(\mathrm{H})$ & 0.07 & 0.04 & 0.90 \\
\hline SWNTs-Phenethyl(L) & 0.18 & 0.14 & 0.57 \\
\hline SWNTs-Phenethyl- $150^{\circ} \mathrm{C}(\mathrm{L})$ & 0.18 & 0.12 & 0.68 \\
\hline SWNTs-Phenethyl- $200^{\circ} \mathrm{C}(\mathrm{L})$ & 0.12 & 0.07 & 0.77 \\
\hline SWNTs-Phenethyl- $600^{\circ} \mathrm{C}(\mathrm{L})$ & 0.08 & 0.04 & 0.95 \\
\hline SWNTs-Phenethyl(H) & 0.33 & 0.28 & 0.34 \\
\hline SWNTs-Phenethyl- $150^{\circ} \mathrm{C}(\mathrm{H})$ & 0.29 & 0.22 & 0.39 \\
\hline SWNTs-Phenethyl- $200^{\circ} \mathrm{C}(\mathrm{H})$ & 0.18 & 0.10 & 0.67 \\
\hline SWNTs-Phenethyl- $600^{\circ} \mathrm{C}(\mathrm{H})$ & 0.09 & 0.05 & 0.90 \\
\hline SWNTs-Bn(L) & 0.19 & 0.14 & 0.59 \\
\hline SWNTs-Bn- $150^{\circ} \mathrm{C}(\mathrm{L})$ & 0.13 & 0.09 & 0.78 \\
\hline SWNTs-Bn-200 ${ }^{\circ} \mathrm{C}(\mathrm{L})$ & 0.13 & 0.08 & 0.87 \\
\hline SWNTs-Bn-600 ${ }^{\circ} \mathrm{C}(\mathrm{L})$ & 0.08 & 0.04 & 0.93 \\
\hline SWNTs-Bn(H) & 0.26 & 0.21 & 0.36 \\
\hline SWNTs-Bn- $150^{\circ} \mathrm{C}(\mathrm{H})$ & 0.16 & 0.08 & 0.73 \\
\hline SWNTs-Bn- $200^{\circ} \mathrm{C}(\mathrm{H})$ & 0.14 & 0.08 & 0.77 \\
\hline SWNTs-Bn- $600^{\circ} \mathrm{C}(\mathrm{H})$ & 0.08 & 0.05 & 0.94 \\
\hline
\end{tabular}
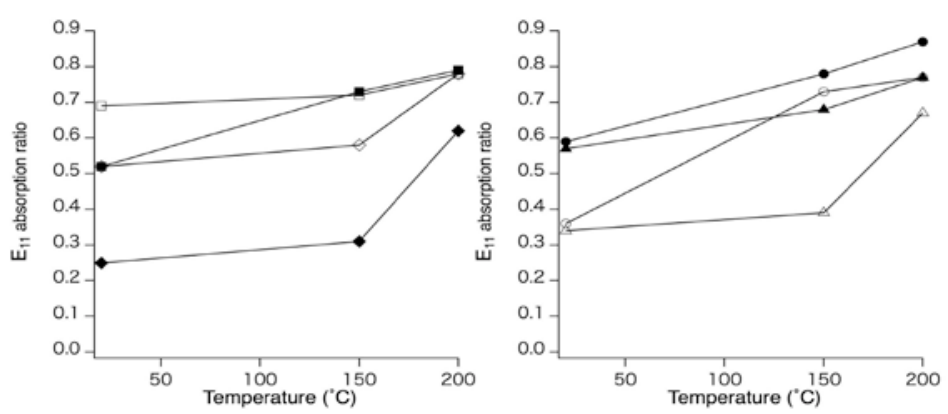

Figure 2. $\mathrm{E}_{11}$ absorption ratio of SWNTs-R as a function of temperature of the thermal

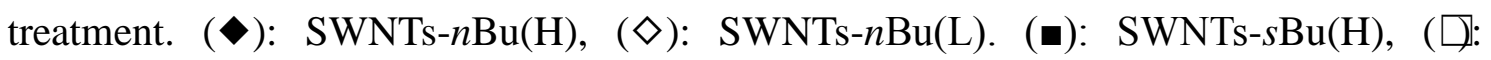

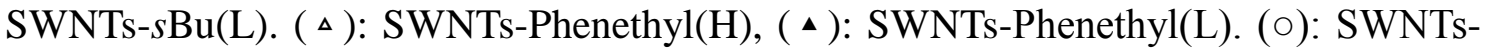
$\mathrm{Bn}(\mathrm{H}),(\bullet):$ SWNTs-Bn(L). 
Figure 3. Relative energies calculated for $n \mathrm{Bu}-(6,6) \mathrm{SWNT}-n \mathrm{Bu}$ isomers. A hydrogenterminated $(6,6)$ SWNT structure containing 21 carbon layers $\left(\mathrm{C}_{252} \mathrm{H}_{24}\right)$ was employed for this calculation. The hydrogen atoms at the edge are omitted for clarity.

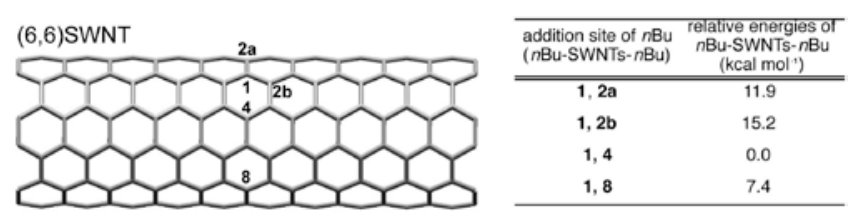

Table 2. Bond-dissociation energies ( $\mathrm{kcal} \mathrm{mol}^{-1}$ ) of (Bu-SWNTs)-Bu and Bu-(SWNT radical). Relative energies are in parentheses.

\begin{tabular}{|c|c|c|c|c|c|c|}
\hline SWNT & (nBu-SWNTs)- & (RBU-SWNTS)- & Bu-SWNTs)-nBu & (ABU-SWNTs)--1Bu & nBBu-(SWNTs radical) & IBu-(SWNTs radical) \\
\hline$(5,5)$ & $42.6(34.2)$ & $31.9(23.5)$ & $44.1(35.7)$ & $28.0(19.6)$ & $323(23.9)$ & $20.2(11.8)$ \\
\hline$(6,6)$ & $42.4(34.0)$ & $30.7(22.3)$ & $42.9(34.5)$ & $24.7(16.3)$ & $31.4(23.0)$ & $19.2(10.8)$ \\
\hline$(7,7)$ & $41.9(33.5)$ & $29.0(20.6)$ & $41.2(32.8)$ & $22.0(13.6)$ & $23.9(15.5)$ & $11.7(3.3)$ \\
\hline$(8,8)$ & $41.4(33.0)$ & $27.3(18.9)$ & $39.5(31.4)$ & 19.7 (19.7) & 20.7 (12.3) & $8.4(0.0)$ \\
\hline
\end{tabular}



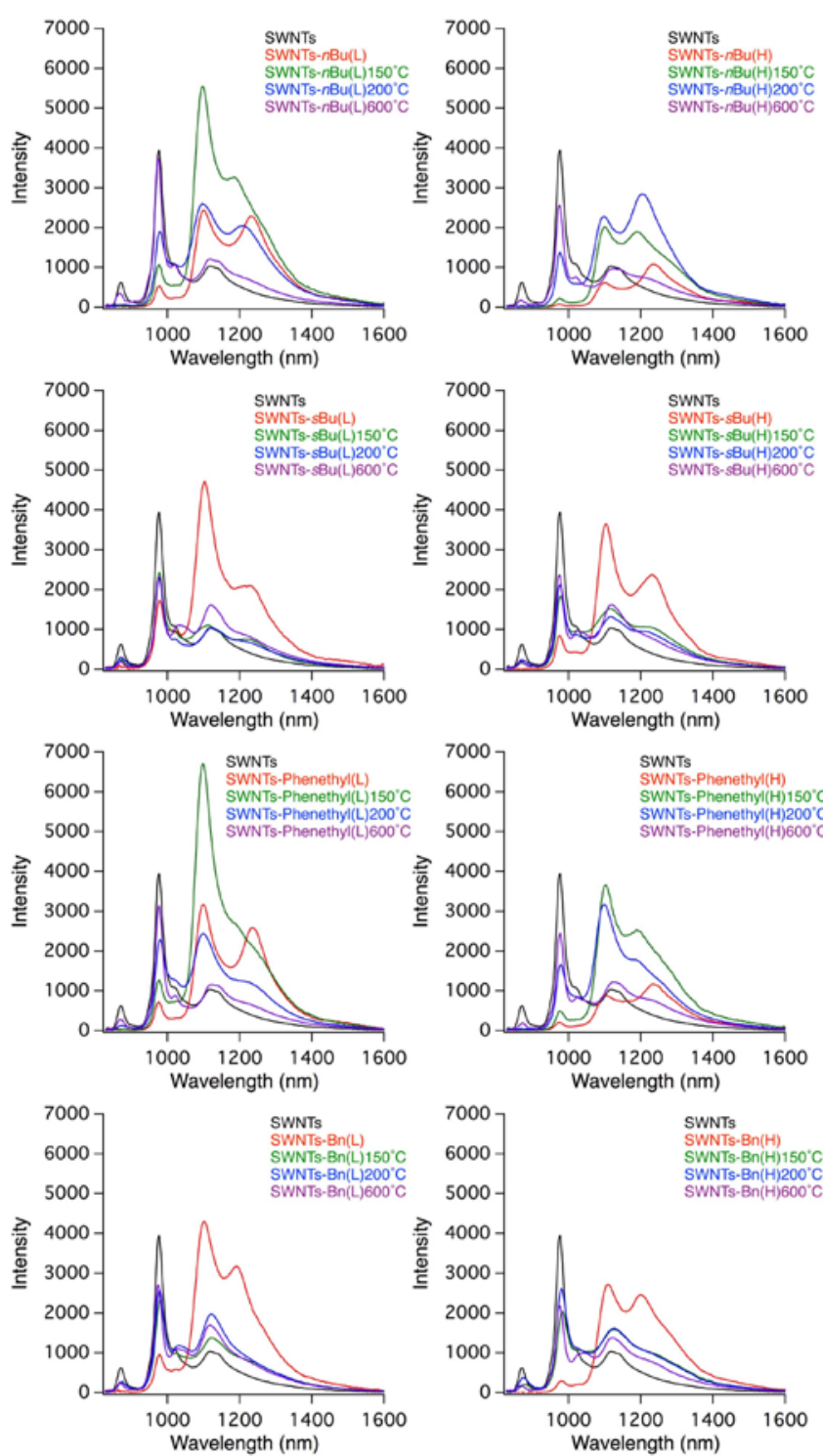

Figure 4. PL spectra of SWNTs and SWNTs-R before and after thermal treatment in a $\mathrm{D}_{2} \mathrm{O}$ solution containing $1 \mathrm{wt} \%$ SDBS. 

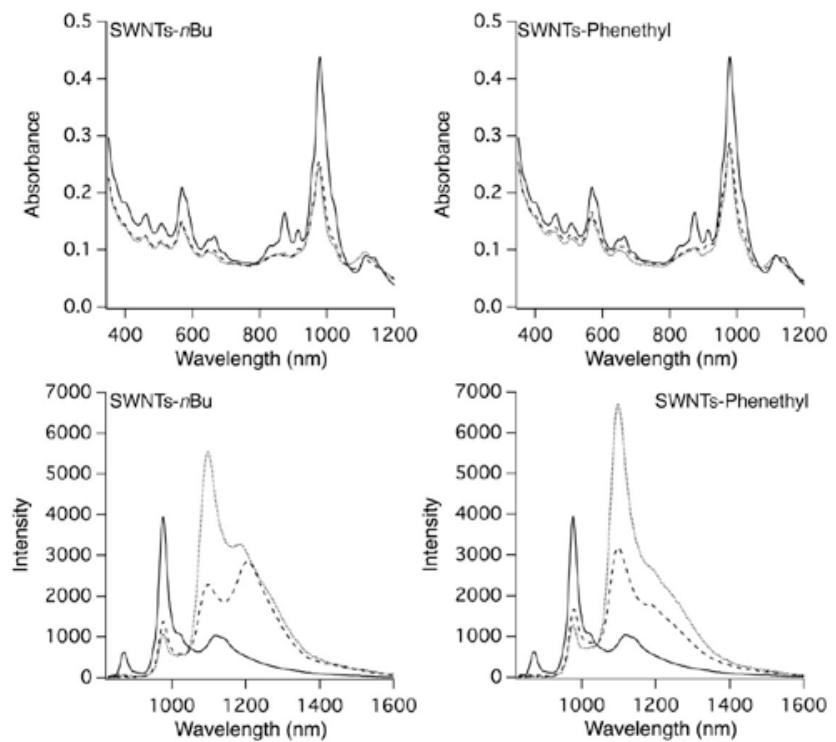

Figure 5. (a) Absorption and (b) PL spectra of SWNTs (solid line), SWNTs-R(L) $150^{\circ} \mathrm{C}$ (dotted line), and SWNTs-R(H)200 ${ }^{\circ} \mathrm{C}$ (dashed line). (Excitation: the $\mathrm{E}_{22}$ energy) 